\title{
O PSICÓLOGO DO TRABALHO NO MUNDO DAS PRÁXIS CAPITALISTA: REFLEXÕES FENOMENOLÓGICO-EXISTENCIAIS ${ }^{1}$
}

\author{
The Psychologist's Work in the World of the Capitalist Praxis: Phenomenological- \\ Existential Reflections \\ El Psicólogo del Trabajo en el Mundo del Praxis Capitalista: Reflexiones \\ Fenomenológico-Existenciales
}

Sylvia Mara Pires de Freitas

\begin{abstract}
Resumo: O presente artigo, a princípio e de uma maneira breve, contextualiza a Psicologia Industrial, Organizacional e do Trabalho, através de suas construções históricas e dos fundamentos filosóficos das respectivas teorias hegemônicas, que alicerçam os saberes e fazeres do psicólogo no contexto do trabalho. Como foco central, apresenta mais uma leitura para esta subárea da Psicologia, através da fenomenologia e do existencialismo sartreano, possibilitando assim, a ampliação das práticas do psicólogo nas relações do, no e com o trabalho, cerceado pelas práxis capitalistas. Finaliza, levantando questões e considerações sobre a vivência do psicólogo do trabalho, quando, ao ajudar o trabalhador a transcender suas tensões entre o mundo interno e externo, também como trabalhador tem os seus valores balizando as suas próprias tensões nesse contexto. Enfoca então, a necessidade do psicólogo ter consciência de suas limitações e dos preconceitos com fenômenos cotidianos, que podem obstruir mudanças da maneira pela qual vivem o mundo do trabalho.
\end{abstract}

Palavras-chave: Fenomenologia; Existencialismo; Psicologia do Trabalho; Práxis Capitalista.

Abstract: This article, primarily and in a brief, contextualizing the Industrial Psychology, Organizational Psychology and Psychology of Work, through its historical constructions and grounds of their philosophical hegemonic theories, which underpin the knowledge and the practices of psychologist in the work. As a central focus, has a further reading for this sub-area of psychology, through phenomenology and existentialism of Sartre, thus enabling the expansion of the practice of psychology in the relations in the work, surrounded by capitalist praxis. Finally, raising issues and considerations on the experience of the psychologist's work, when, to help the worker to transcend the tensions between its internal and external world, as well as employee has their values marked its own tensions in that context. Then focuses on the need for psychologists to be aware of their limitations and prejudices with everyday phenomena, which can block changes in the way in which live the world of work.

Keywords: Phenomenology; Existentialism; Psychology of Work; Praxis Capitalists.

Resumen: Este artículo, en principio y brevemente, contextualiza la Psicología Industrial, Psicología Organizacional y Psicología del Trabajo, por sus construcciones históricos y los motivos de sus teorías filosóficas hegemónicos, que sustentan el conocimiento y el costumbre del psicólogo en el trabajo. Como eje central, tiene una lectura adicional para este sub-área de la psicología, motivada por la fenomenología y el existencialismo de Sartre, lo que permitirá la expansión de la práctica de la psicología en las relaciones en el trabajo, rodeado de la praxis capitalista. Por último, plantear cuestiones y consideraciones sobre la experiencia de la labor del psicólogo, cuando, para ayudar al trabajador a superar las tensiones entre su mundo interno y externo, así como empleado tiene sus valores marcados sus propias tensiones en ese contexto. A continuación, se centra en la necesidad de psicólogos que ser conscientes de sus limitaciones y los prejuicios con los fenómenos cotidianos, que pueden bloquear los cambios en la forma en que vive el mundo del trabajo.

Palabras-clave: Fenomenología; Existencialismo; Psicología del trabajo; Praxis capitalistas.

"Toda a aventura humana, pelo menos até aqui, é uma luta obstinada contra a escassez." (Jean-Paul Sartre, Critica da Razão Dialética)

Trabalho apresentado no I Congresso Sul-Brasileiro de Fenomenologia \& I Congresso de Estudos Fenomenológicos do Paraná, realizado na Universidade Federal do Paraná (UFPR), em Curitiba, de 04 a 07 de junho de 2009.

\section{Introdução}

Muitos dos psicólogos que atuam no campo da Psicologia direcionada ao contexto do trabalho conhecem os percalços que dificultam, muitas das vezes, a obtenção de seus projetos.

Acredito que quatro dos grandes legados para as dificuldades encontradas neste campo de atuação, no Brasil, foram: (a) o início de suas atividades se darem no bojo em que a história se construía através de práxis capita- 
lista; (b) as atividades eram exercidas, inicialmente, por outros profissionais que não os psicólogos; (c) a abolição da disciplina de Filosofia no sistema educacional, pelo regime ditatorial, da década de 60 ao início da de 80 e; (d) o ensino tecnicista da década de 70 que premiava o fazer sobre o saber.

Do primeiro, a Psicologia herdou a pressão para corresponder às necessidades daqueles que ocupam um lugar de hegemonia; do segundo, a falta de identidade própria nos seus saberes e fazeres, haja vista que estes procediam de outras disciplinas como a Administração, a Medicina, a Pedagogia e a Engenharia; do terceiro, a precarização do conhecimento dos psicólogos dos fundamentos teórico-epistemológicos que fundamentam suas práticas, corroborado pelo quarto legado, cuja preocupação era mais com o fazer do que com o saber, desconsiderando que são ações interdependentes.

Acho factível que, somente no início da década de 80, a Psicologia começou a cunhar nos seus saberes e fazeres, uma política que buscou e ainda busca romper com os legados acima mencionados. Com relação às teorias, hoje, observa-se autonomia dos psicólogos, inclusive nas escolhas das interfaces teóricas, podendo, agora optar pelas mais coerentes com seus ideais; todavia, ainda nas práticas, por estas continuarem a ser exercidas no mundo prático-inerte construídos por práxis capitalista, ainda encontram-se muitas limitações para superá-lo.

Não obstante a essas práxis econômica e social e por acreditarem na necessidade de transcender políticas de gestões que contribuam com a criação e manutenção do status quo de projetos hegemônicos, bem como cooperem na promoção da saúde física e mental dos trabalhadores é que muitos psicólogos persistem neste projeto.

Neste artigo, abordaremos a interface da Psicologia com a Filosofia, especificamente com a Fenomenologia e o Existencialismo sartreano, abordagens que respaldam meus trabalhos como docente e orientadora de estágio no campo da Psicologia do Trabalho.

O início de minha atuação fundamentada nesta abordagem, deu-se na área clínica. Sempre atuei em ambas as áreas paralelamente; no entanto, custou-me um bom tempo para ousar lançar este olhar para o contexto do e no trabalho.

Terminada minha formação em Psicologia na metade da década de 80, os saberes e fazeres da Psicologia Industrial, principalmente, e da Organizacional me embriagaram, limitando minha propensão ao risco de transcendê-los. Destarte, ao me perceber contraditória entre minha concepção de ser humano e as práticas que executava e/ou orientava, vi-me constrangida, por mim mesma, a afirmar a compatibilidade entre elas. Paulatinamente, arrisquei introduzir os fundamentos fenomenológicoexistenciais no contexto do trabalho e, como todas as demais interfaces da Psicologia, esta apresenta suas possibilidades e limitações; todavia, transpus minha inquietação, compreendendo o quanto é importante a coerência entre a teoria e a prática e o compromisso em ajudar os trabalhadores a terem consciência reflexiva sobre como existem no mundo do trabalho e o que fazem nele e dele. Nesta categoria, também incluo aqueles que representam a supremacia, uma vez que também são trabalhadores.

Por uma questão didática, prosseguirei este artigo dividindo-o em três partes: na primeira, farei um breve resgate histórico sobre os caminhos percorridos pela Psicologia no contexto do trabalho, dando enfoque aos critérios para análise crítica das teorias que dão identidade a sua mais recente face ${ }^{2}$ : a da Psicologia do Trabalho; na segunda, situarei o leitor, também brevemente, sobre os fundamentos filosóficos fenomenológico-existenciais, respectivamente de Husserl e Sartre, e, por fim, na terceira, buscarei realizar algumas reflexões, balizando-me nas referidas abordagens, sobre as possibilidades e limitações da prática do psicólogo no contexto do trabalho frente às contradições do mundo capitalista.

\section{A Psicologia no Contexto do Trabalho: História e Fundamentos das Teorias Hegemônicas}

A Psicologia no contexto do trabalho iniciou suas atividades no Brasil por volta da década de 30 e pelas mãos de outros profissionais, a saber: os administradores, os educadores, os engenheiros e os médicos, como disse anteriormente. As atividades iniciadas naquela época eram direcionadas ao trabalhador e sua função, tais como a análise e descrição de cargos; recrutamento e seleção; orientação profissional; dentre outras, baseando-se praticamente na psicometria. Atribuía-se mais importância à técnica, à testagem e aos seus resultados e classificações, e menos aos seus fundamentos e ao processo de construção. Buscava-se enquadrar e ajustar o trabalhador às suas funções, sendo estas últimas de maior importância que o primeiro.

O ser humano cria o trabalho como ação sobre o mundo a fim de suprir suas necessidades; no entanto, com 0 processo de industrialização, o trabalhador sentiu a contra finalidade da matéria, ou seja, o criador (trabalhador) tornou-se escravo de sua criatura (meios e modos de produção). Assim, escravizados as normas e procedimentos, era necessário que todos os esforços daqueles que trabalhavam em prol da Psicologia Industrial buscassem acomodar o trabalhador ao que já fora construído para ele executar.

No ano de 1962, quando a Psicologia foi regulamentada enquanto profissão, ainda havia uma cultura voltada para as práticas da Psicologia Industrial ou Psicologia da Indústria como foi cunhada. No início da década de

\footnotetext{
Utilizo a expressão face com fundamento no autor Sampaio (conforme citado por Freitas, 2002), que coloca que os diferentes momentos da construção desta subárea da Psicologia teriam suas faces compreendidas na Psicologia Industrial, na Psicologia Organizacional e na Psicologia do Trabalho, as quais atualmente coexistem no mesmo contexto.
} 
70, quando o Brasil, no auge do regime militar abre suas portas para importação, fundamentando-se no discurso do crescimento do país, também foram importadas, grande parte das Teorias das Organizações. Nesta época, mesmo ampliando sua micro visão do homem-função, para a organização como todo, essas teorias continuaram se apoiando nos paradigmas da Administração. Provavelmente, a pouca identificação do psicólogo com as práticas dessas teorias, e por não serem fundadores de grande parte das mesmas, sobressaíram mais os seus fazeres do que seus saberes.

Houve um modismo no Brasil construído pela reprodução alienada dessas teorias, que adentraram a década de 80. Tive a oportunidade de vivenciar o frenesi das implantações de Programas de Qualidade Total, no qual participei como psicóloga em uma empresa estatal, e que, também de maneira alienada, não me atentava na época que, se uma empresa atinge sua Qualidade Total, ela vai ao encontro de sua morte, visto que totalizar-se é negar quaisquer possibilidades de construção de novos projetos, logo chega ao seu fim.

Até os anos 80, o Brasil vivia sob o forte mando do regime militar. A educação tinha um foco no trabalho, ou seja, o lema era aprender para fazer. Desta maneira o cunho tecnicista e a influência da disciplina Administração corroboraram com a construção científico-metodológica da Psicologia no contexto do trabalho.

De 80 a 85, o regime militar no Brasil teve seu último comando do então Presidente João Batista Figueiredo. No entanto, o regime ditatorial estava mais ameno. Em 1980, alguns acontecimentos políticos e sociais como, p.e, a criação da Associação Brasileira de Psicologia Social (Abrapso), incrementam os questionamentos de psicólogos sociais críticos ao fazer positivista desta área, que se respaldava na Psicologia social americana, ajudando a Psicologia no contexto do trabalho, no Brasil, a tomar novos rumos. Começaram então, produções científicas de profissionais brasileiros, dentre eles Codo e Lane (conforme citados por Freitas, 2002) que ajudaram a construir uma identidade do profissional da área, dando sentido para suas atividades. Práticas mais reflexivas começaram também a dividir espaço com o saber tecnicista e, como a produção dessa nova identidade da Psicologia no contexto do trabalho, em grande parte, advém de psicólogos docentes universitários, há uma exigência de conhecer os fundamentos das práticas propostas, bem como o cunho crítico deste movimento dá o lugar principal aqueles que, até então, eram os atores coadjuvantes: os trabalhadores. A comunhão, pela interdependência entre o saber e o fazer da Psicologia do Trabalho, bem como a necessidade de focar fenômenos relacionados à saúde mental do trabalhador começam a firmar a identidade dos psicólogos.

\section{O Fazer que Deve Conhecer seu Fundamento}

Construindo-se desde a década de 80 dentro da própria casa, ou seja, pelos próprios psicólogos brasileiros, a Psicologia do Trabalho, terceira identidade desta subárea da Psicologia, que sucedeu e ainda divide espaço com a Psicologia Industrial e a Psicologia Organizacional, começa e prossegue fundamentando a maioria de seus fazeres à luz de teorias psicológicas e interfaces com outras disciplinas, principalmente as de cunho social , como podemos observar no Quadro 1, página seguinte.

Observamos no quadro anterior, que toda prática fundamenta-se em um olhar teórico, e este último em questões filosóficas. Desta maneira, não há fazeres sem fundamentarem-se em saberes, o que torna mister que o profissional da área tenha bem claro sob qual viés suas práticas serão apoiadas. Com isto, evita-se o ecletismo silvestre de práticas que corroboram com a pouca valorização e respeito para com a área, bem com a falta de sentido de suas técnicas.

Cada teoria possui em seu bojo uma verdade sobre o mundo, isto é, a sua questão ontológica. Toda teoria possui um conjunto de conhecimentos - a questão epistemológica - que a legitima como conhecimento científico. A respectiva concepção de ser humano embasa suas práticas que, por sua vez mostram a sua ética para com este. Também mostram o tipo de mudança que vai ou não provocar no contexto que for aplicada.

Assim, o conhecimento sobre que teoria respalda uma prática é extremamente necessário, uma vez que é a partir da teoria que serão definidos os métodos e procedimentos, bem como sob qual visão sustentará a análise dos fenômenos objetivados. Utilizar a técnica sem seu conhecimento teórico é como dar "tiro no escuro": podemos acertar naquilo que não propusemos ou mesmo não reconhecermos o fenômeno quando esse aparece. Enfim, podemos nos perder em nossa própria prática, uma vez que não sabemos de onde precede e a que ela se propõe.

No Brasil, a abordagem Fenomenológico-existencial já se consolidou na prática clínica; no entanto, ainda é bem escasso seu uso no contexto do trabalho. Apesar das abordagens qualitativas buscarem o fenômeno e não os fatos, pouco se encontra produções científicas baseadas em Sartre, que contemplam o contexto da Psicologia do Trabalho.

Devido a isto, considero um privilégio poder levar aos leitores algumas reflexões que contribuem na inovação dos conhecimentos para esta área. Prosseguimos então, situando brevemente, os fundamentos da Fenomenologia e do Existencialismo sartreano.

\footnotetext{
V. análise crítica das teorias hegemônicas das fases/faces da Psicologia Industrial e Psicologia Organizacional em Guareschi e Freitas (2004, p. 45-46).
} 
Quadro 1 - Face da Psicologia do Trabalho e critérios para análise crítica das teorias hegemônicas

\begin{tabular}{|c|c|c|c|c|}
\hline & \multicolumn{4}{|c|}{ PSICOLOGIA DO TRABALHO } \\
\hline & $\begin{array}{l}\text { Teorias sobre } \\
\text { estresse }\end{array}$ & $\begin{array}{l}\text { Psicodinâmica } \\
\text { do trabalho }\end{array}$ & $\begin{array}{l}\text { Abordagens de base } \\
\text { epidemio lógicas e/ou } \\
\text { diagnósticas }\end{array}$ & $\begin{array}{l}\text { Estudos e pesquisas em } \\
\text { subjetividade e trabalho }\end{array}$ \\
\hline $\begin{array}{l}\text { Referencial } \\
\text { Teórico }\end{array}$ & $\begin{array}{l}\text { - Cognitivo-Comportamental. } \\
\text { - Psicologia Social Científica. }\end{array}$ & - Psicanálise. & $\begin{array}{l}\text { - Teorias Marxistas. } \\
\text { - Psicologia Social } \\
\text { Histórico-Crítica. }\end{array}$ & $\begin{array}{l}\text { - Psicanálise. } \\
\text { - Psicologia Social Histórico- } \\
\text { Crítica. }\end{array}$ \\
\hline Meta Física & $\begin{array}{l}\text { - } 0 \text { estresse não é uma doença, mas } \\
\text { uma tentativa de adaptação e não } \\
\text { está relacionado apenas ao trabalho, } \\
\text { mas ao cotidiano de vida experimen- } \\
\text { ta do pelo sujeito. } \\
\text { - A atividade cognitiva media as } \\
\text { respostas do indivíduo ao seu meio } \\
\text { ambiente e, em alguma extensão, } \\
\text { dita o grau de ajustamento ou mau } \\
\text { ajustamento do indivíduo. } \\
\text { - } 0 \text { trabalho é desencadeador do } \\
\text { processo de estresse. }\end{array}$ & \begin{tabular}{|l} 
- 0 desejo do trabalhador \\
x demanda do trabalho. \\
- A organização do traba- \\
Iho se apresenta como \\
uma "porta de entrada" \\
do sofrimento e doença \\
mental enquanto gera- \\
dora de angústia e de \\
estratégias defensivas. \\
- Ausência de ênfase na \\
patologia.
\end{tabular} & $\begin{array}{l}\text { - Trabalho como fator } \\
\text { constitutivo de quadros } \\
\text { psicopatológicos e do } \\
\text { processo saúdeldoença } \\
\text { mental, e não, tão } \\
\text { somente, como desen- } \\
\text { cadeante. }\end{array}$ & $\begin{array}{l}\text { - Realidade não essencialista elou } \\
\text { - Nesenvolvimentista. } \\
\text { - Não há dicotomia entre indivíduo } \\
\text { e coletivo; subjetividade e obje- } \\
\text { tividade. } \\
\text { - Em oposição as concepções de } \\
\text { sujeito autônomo e livre asso- } \\
\text { ciadas a idéia de indivíduo. } \\
\text { - Ausência de ênfase na patologia. }\end{array}$ \\
\hline Epistemologia & $\begin{array}{l}\text { - Compreensão dos comportamentos } \\
\text { e representações cognitivas disfun- } \\
\text { cionais, aprendidas e reforçadas pela } \\
\text { experiência familiar e social. }\end{array}$ & $\begin{array}{l}\text { - Compreensão das re- } \\
\text { presentações dos traba- } \\
\text { Ihadores de suas expe- } \\
\text { riências no cotidiano de } \\
\text { trabalho e nas situações } \\
\text { de adoecimento }\end{array}$ & $\begin{array}{l}\text { - Compreensão da(s) } \\
\text { história(s) produzida(s) } \\
\text { pelas relações dialéti- } \\
\text { cas entre ser humano- } \\
\text { trabalho. }\end{array}$ & $\begin{array}{l}\text { - Compreensão dos modos de } \\
\text { subjetivação relacionados ao } \\
\text { trabalho. } \\
\text { - Desconstrução do discurso cien- } \\
\text { tífico (hermenêutica crítica). }\end{array}$ \\
\hline Ser Humano & $\begin{array}{l}\text { - Um ser bio- psicossocial, ou seja, } \\
\text { age em ambientes biológicos, psico- } \\
\text { lógicos e sociais, respondendo a eles } \\
\text { de maneira integrada. }\end{array}$ & - Sujeito desejante. & $\begin{array}{l}\text { - Constitui-se a partir } \\
\text { das relações, que por } \\
\text { sua vez são contínuas. }\end{array}$ & $\begin{array}{l}\text { - Sujeito vinculado as normas } \\
\text { sociais e constituído nas tramas } \\
\text { que definem tais normas. }\end{array}$ \\
\hline Ação Mudança & $\begin{array}{l}\text { - Prevenção e intervenção voltadas, } \\
\text { preferencialmente, para o gerencia- } \\
\text { mento individual do estresse através } \\
\text { de mudanças cognitivas e compor- } \\
\text { tamentais, e práticas de exercícios } \\
\text { físicos e relaxamento. }\end{array}$ & \begin{tabular}{|l|} 
- Denúncia do sofrimento \\
causado pelo trabalho \\
e as defesas coletivas \\
contra a doença. \\
- Mudança Interpretativa. \\
- Interativa.
\end{tabular} & $\begin{array}{l}\text { - Identificar a relação } \\
\text { entre a condição de } \\
\text { vida e de trabalho e o } \\
\text { surgimento, a freqüên- } \\
\text { cia e a gravidade dos } \\
\text { distúrbios mentais. }\end{array}$ & $\begin{array}{l}\text { - Buscam as experiências dos } \\
\text { sujeitos e as tramas que cons- } \\
\text { troem o lugar do trabalhador, } \\
\text { definindo modos de subjetivação } \\
\text { relacionados ao trabalho. }\end{array}$ \\
\hline $\begin{array}{l}\text { Práticas } \\
\text { Consolidadas }\end{array}$ & $\begin{array}{l}\text { - Avaliação cognitiva da situação } \\
\text { (o fator estressor) que determina } \\
\text { por que e quando esta situação } \\
\text { é estressora e para o esforço de } \\
\text { enfrentamento, ou seja, a mudança } \\
\text { cognitiva e comportamental diante } \\
\text { do estressor. Introduzem o conceito } \\
\text { de coping (sem tradução em portu- } \\
\text { guês) para se referirem ao conjunto } \\
\text { de estratégias cognitivas e compor- } \\
\text { tamentais utilizadas para avaliar e } \\
\text { gerenciar as exigências internas e/ou } \\
\text { externas, com base nas experiências } \\
\text { pessoais e nas especificidades do } \\
\text { estímulo (novidade, previsibilidade, } \\
\text { intensidade, p.e.). }\end{array}$ & $\begin{array}{l}\text { - Voltam-se para a } \\
\text { coletividade (e não } \\
\text { indivíduos isolados) e } \\
\text { para aspectos da orga- } \\
\text { nização do trabalho a } \\
\text { que os indivíduos estão } \\
\text { submetidos }\end{array}$ & $\begin{array}{l}\text { - Práticas pluridimen- } \\
\text { sionais. Recorrem na } \\
\text { busca de informações, } \\
\text { a todos os instrumen- } \\
\text { tos disponíveis: obser- } \\
\text { vações, questionários, } \\
\text { entrevistas, fontes } \\
\text { documentais, dados } \\
\text { estatísticos variados, } \\
\text { análise das tarefas, } \\
\text { dentre outras. }\end{array}$ & $\begin{array}{l}\text { - Estudos de temas como: } \\
\text { - gênero; } \\
\text { - etnia; } \\
\text { - processo de trabalho; } \\
\text { - transformações tecnológicas e } \\
\text { organitivas; } \\
\text { - privilegiam as experiências e } \\
\text { vivências dos trabalhadores } \\
\text { sobre o cotidiano de vida e de } \\
\text { trabalho enquanto expressões } \\
\text { do sujeito na intersecção de sua } \\
\text { particularidade com o mundo } \\
\text { sócio-cultural e histórico. } \\
\text { - privilegiam as vivências de } \\
\text { sofrimento e adoecimento sem } \\
\text { privilegiar, necessariamente, os } \\
\text { diagnósticos clínicos. }\end{array}$ \\
\hline
\end{tabular}

\footnotetext{
${ }_{4}$ Confeccionei quadro similar em minha dissertação (Freitas, 2002, p. 40-41), sendo publicado em artigo (Guareschi e Freitas, 2004, p. 4546). Neste artigo, este foi reformulado e atualizado com base no exposto por Jacques (2003), sendo realizadas as devidas complementações. Ressalto que, em conversa com a Profa. Dra. Maria da Graça Corrêa Jacques sobre seu referido artigo, esta enfatizou que a leitura que fez das abordagens teórico-metodológicas em saudeldoença mental e trabalho é "[...] um modo de interpretar, e, portanto sujeito a outros 'olhares' "(sic). Observação que também considero importante e aqui a ratifico.

5 Segundo Jacques (2003, p. 11 1) esses estudos "[...] se alicerçam em postulados derivados de diferentes campos disciplinares no âmbito das ciências sociais". No quadro foram destacados os mais hegemônicos.
} 


\section{A Fenomenologia como Método}

Ao propor o estudo dos fenômenos, Husserl (1980) objetiva descrever sua estrutura específica que é constituída pela própria consciência. Concebendo-a como um ato, Husserl declara que não são as coisas do mundo que vão até à consciência, mas o contrário, é esta que os capta e lhes dá um sentido ideal, o que confere à consciência o adjetivo transcendental.

Ser consciência transcendental é intencionar o mundo, é ser consciência-de-algum-objeto, daí deriva-se também outra característica da consciência husserliana: o princípio da intencionalidade. Partindo deste princípio, a intuição, entendida como conhecimento imediato que independe de qualquer processo de raciocínio, é o ponto de partida de todo ato intencional. Este último, por sua vez, é transitório, passageiro. Sendo transiente o ato intencional, a compreensão dos fenômenos deve ser direcionada à relação consciência-mundo e não às relações causais.

Tal concepção rompe com o paradigma positivista, no seu absolutismo e maneira naturalizante de explicar o mundo. A Fenomenologia torna-se o "método da crítica do conhecimento universal das essências" (Galeffi, 2000, p. 14). As coisas estão no mundo, mas só terão o caráter existencial sendo significadas por uma consciência, caso contrário não terão sentido, só estarão postas no mundo enquanto em-si (coisa). No entanto, a via não é de mão única. Há uma interdependência entre consciência e mundo. A primeira, para existir, precisa de um mundo para significar e o segundo precisa da consciência para ser significado. Não sendo duas entidades independentes, só podem se definir a partir desta correlação: o eu e a coisa, o nada e o ser. A compreensão do fenômeno, então, revela-se mais como uma postura, uma atitude compreensiva do que como uma atitude explicativa.

A facção dos profissionais da Psicologia do Trabalho que lança mão de pressupostos fenomenológicos, intenciona a compreensão do mundo do vivido, da experiência do trabalhador. Como esse significa sua relação no, do e com o trabalho. E para atingir tal compreensão há a necessidade da utilização do que Husserl (1980) definiu como o método fenomenológico: a redução fenomenológica ou epoqué.

A grosso modo, para Husserl (1980), a fim de se compreender como o ser humano compreende o mundo, há a necessidade daquele que busca a compreensão, estar livre de quaisquer conhecimentos, crenças, atitudes e/ou julgamentos, ou seja, deve colocar entre parênteses como é o mundo exterior para ele próprio, para que assim possa compreender a experiência do vivido pelo outro, sem contaminação pelas suas próprias.

No entanto, Sartre e Merleau-Ponty (conforme citado por Morris, 2009) discordam de Husserl quanto à possibilidade de haver suspensão de juízos "[...] acerca da verdade das pretensões de existências feitas pelos objetos percebidos" (p. 57), haja vista que para eles o idealismo de Husserl separa, na descrição, o como as coisas são para a consciência que as apreende de como elas realmente são no mundo.

Para Sartre, não há dicotomia entre aparência e essência, estando a raiz do significado das palavras e das coisas (essências) na existência (mundo experienciado). Morris (2009) menciona que, Sartre e Merleau-Ponty “[...] diferentemente de Husserl, não colocam a existência 'entre parênteses', eles aparentemente fazem a própria assunção que está aberta à refutação" (p. 59) ${ }^{6}$.

Compreendo que abrem à refutação por ser o ser humano criador da sua essência, sendo esta passível a mudança. Os fenômenos que a fenomenologia busca descrever são familiares, sem o contraste, os fenômenos cotidianos parecem-nos garantidos, uma vez que são base de qualquer pensamento. Por eles temos dificuldade de nos maravilhar, o que torna difícil suas descrições. (Morris, 2009)

Assim, da Fenomenologia, lanço mão dos conceitos de consciência intencional e o método fenomenológico, compreendendo-o, tal qual Sartre e Merleau-Ponty (mencionados em Morris, 2009), não como um método introspectivo, mas como descritivo do mundo, da realidade humana e passível de mudança a partir do momento que a essência dada a ele é posta em dúvida e assim aceita.

Reconhecendo então, a mutabilidade das essências por serem criações humanas, baseio-me também nos conceitos existenciais sartreanos e no método progressivo regressivo, haja vista que em sua Filosofia da existência, Sartre (1943/2005) coloca que não basta compreender o mundo, é necessário transformá-lo. Uma atitude da modernidade que visa à justiça social.

Prosseguirei, apresentando brevemente os fundamentos sartreanos da existência.

\section{O Existencialismo Sartreano}

Foi em 1933 que Sartre teve contato com a Fenomenologia de Husserl (Beauvoir, 1961/1984). Pela sua necessidade de falar da concretude do mundo e ser considerada Filosofia, Sartre motivou-se perante a possibilidade dada pela Fenomenologia de "ultrapassar a oposição do idealismo e do realismo, afirmar a um tempo a soberania da consciência e a presença do mundo tal como se dá a nós" (Beauvoir, 1961/1984, p. 138), viabilizando a relação dialética entre subjetividade e objetividade.

A superação desse dualismo leva Sartre a afirmar que não há dicotomia entre essência e aparência, como dito anteriormente. Não há algo atrás do ser humano que sua aparência não mostre. Se a aparência revela a essência, para Sartre (1943/2005), as aparências não enganam. O ser humano é como se mostra no mundo, mas não se reduz a sua manifestação, haja vista que possui infinitas possibili-

\footnotetext{
${ }^{6}$ Grifo da autora.
} 
dades de manifestar-se no mundo, bem como de significálo. Assim, a essência de algo é infinita e inesgotável.

Além da intencionalidade, a temporalidade é outra característica da consciência husserliana. Visando sempre algo, a consciência é voltada para o futuro, de acordo com o fim que deseja atingir. Não é sem propósito que significamos algo de uma maneira ou de outra. A diversidade de significados que as coisas do mundo podem ter está relacionada ao projeto que se tem para com elas. Podemos ilustrar com a diversidade de ideologias sobre o trabalho construídas ao longo da história que ora o desprezam ora o exaltam (Carmo, 2005). Mesmo que, didaticamente, esse autor as situa ao longo da linha histórica, nem todos os seres humanos que pertencem a uma mesma época oferecem a mesma idéia ao trabalho ${ }^{7}$. Até porque se fosse o contrário, uma ideologia não seria transcendida, bem como não as encontraríamos convivendo na mesma época em micro e macro culturas.

Resgatando a questão da temporalidade, a consciência intencional é atemporal. Nossa maneira de significar o mundo vai ao encontro do nosso projeto para com ele. Transcendemos o futuro, ascendemos às experiências passadas para realizarmos nossas escolhas no presente. Passado, presente e futuro não existem linearmente. $\mathrm{O}$ sentido do tempo é dado pela consciência.

No entanto, nem sempre temos consciência reflexiva sobre nossos projetos, ou seja, nem sempre tomamos nossa própria consciência como ponto de reflexão para conhecermos como significamos o mundo. Muitas das vezes, nossa consciência é irrefletida, somente capta o objeto no mundo e dá-lhe o significado. É geralmente o que ocorre dentro de uma cultura, onde crenças, valores, atitudes são repetidos e mantidos sem serem tomados como ponto de reflexão. A irreflexão da própria consciência é o que colabora para a perpetuação de supostas verdades. Para Sartre (1943/2005) o conhecimento só se dá quando a coisa que a consciência intenciona, e que se torna a própria consciência, é tomada como objeto de reflexão e, somente a partir desse conhecimento, que podemos mudá-lo, assumindo autenticamente a responsabilidade pela liberdade da consciência intencional.

Não ter esse conhecimento não retira do ser humano sua responsabilidade pela maneira como significa o mundo. Mesmo irrefletidamente, o ser humano age sobre o mundo conforme o sentido que ele lhe dá. Assim sendo, para Sartre (1943/2005), a práxis, ou seja, a interiorização do exterior (apreensão do mundo, objetividade subjetivada) não é dicotomizada da exteriorização do interior (subjetividade objetivada). Nesta relação dialética, o que o ser humano escolhe para si, também escolhe para o mundo e constrói sua história. É somente desta maneira que Sartre acredita na humanização do mundo e no fazer da

\footnotetext{
Acredito sim, que tais ideologias são representativas de indivíduos cujo projeto objetiva mantê-las a fim de benefícios próprios, desejando transformá-las em verdades absolutas, através de relações de poder.
}

ciência, pois para esse autor, não basta conhecer o mundo, mas tem que se ter a capacidade de alterá-lo.

A partir desta compreensão sartreana, também lançamos mão do método progressivo regressivo, que junto à descrição fenomenológica, nos ajuda a compreender o fenômeno que emerge a partir do próprio indivíduo sobre a situação que ele retrata, o seu vivido, temos a compreensão crítica que

(...) implica vislumbrar outras possibilidades diferentes daquelas escolhidas pelo sujeito em sua história, bem como a elucidação do caminho que percorreu, instrumentos de reflexão ou de alienação que lançou mão e que caracterizaram seu movimento vivido (Maheirie \& Pretto, 2007, p. 460).

Sartre (1960/2002) faz uma diferenciação entre o social e a sociabilidade. A integração social não é o mesmo que sociabilidade. É através do primeiro que ocorre a busca pela imposição dos valores, regras, normas, atitudes, objetivos, formas de vida, enfim, o social sugere que as verdades existem objetivamente no mundo, e que devem determinar nossa existência. Já a sociabilidade direciona-se às relações entre as consciências livres, ou seja, a alteridade e a intersubjetividade.

A questão da sociabilidade para Sartre (1960/2002) é paradoxal. Apoiando-se no princípio da escassez, Sartre menciona que os indivíduos se unem a fim de lutarem contra a xigüidade. A negação do não-ser, ou seja, do nada como essência da consciência, os impulsiona à busca da satisfação de suas necessidades, de uma completude. No entanto, a insuficiência de recursos no mundo reduz a possibilidade de êxito. Por isso, a sociabilidade sartreana é um paradoxo: ao mesmo tempo em que um indivíduo precisa do outro para minimizar as conseqüências da escassez, esta existe justamente pela existência do outro. O outro, ao mesmo tempo em que deve ser um aliado, também é um rival.

Indo além da escassez da natureza e de legados de nossos antepassados, chamado por Sartre (1960/2002) de mundo prático-inerte (o mundo da práxis), e aproximando-se da concepção marxista de classe social, não podemos negar que há um mundo histórico construído pelas divisões sociais do trabalho, que também corroboraram na produção de escassezes. A redução de espaços concretos a serem trabalhados, como o mercado de trabalho e de posições sociais que prestigiam poucos, seriam exemplos dessa construção social que limita as possibilidades do indivíduo.

Continuando a questão da sociabilidade para Sartre (1960/2002), este autor faz distinção entre série e grupos como formas diferentes de estruturas sociais. As séries correspondem a um ajuntamento de pessoas ligadas por algum evento do exterior, como p.e., fila de banco. Seus membros representam uma pluralidade de solidões. O projeto é comum, mas individual. 
Para que os grupos sejam assim identificados, há a necessidade de haver projeto em comum, todos os membros devem perseguir o mesmo fim e cada membro deve assumir o compromisso de fazer parte do grupo. Sartre (1960/2002) menciona que tal compromisso ou juramento de seus membros por converter sua práxis individual em práxis grupal, passa a ser controlado por todos do grupo, entre si, a fim de que ninguém desonre o juramento. No entanto, a manutenção do grupo diante as ameaças das possibilidades de escolhas individuais em retornar à série, é exercida, como define Sartre, através de laços de terror. O medo de que o grupo se dissolva em série ordena a ameaça de se usar a violência, mesmo que velada, como p.ex., o assédio moral, para a sua manutenção.

Quando os próprios membros não conseguem mais manter o grupo por si, pode aparecer a figura do soberano. Este pode ser instituído pelo próprio grupo ou apropriar-se do mesmo. No entanto, o problema maior é que o soberano buscará liderar o grupo de maneira a fazer com que os seus projetos tenham primazia e para atingir seus objetivos, quase sempre precisará do outro. No exercício da soberania reside um projeto perverso: o não reconhecimento da humanidade do Outro. Através da reciprocidade negativa, a reificação do Outro é necessária, uma vez que é imputado no outro uma práxis com fins alheios.

Para finalizar esta breve explanação sobre a questão da sociabilidade em Sartre, oferecendo um resumo sobre a gênese dos grupos, podemos entender que da série formam-se os grupos-em-fusão, que se juntam espontaneamente para combater uma ameaça. Após a obtenção deste projeto, há a ameaça de que seus membros retornem à série. Caso queiram manter o grupo há a necessidade de que seus integrantes jurem não o abandonarem, mas diante da possibilidade de traição, cada membro do grupo controla a si e aos outros por meio da fratenidade-terror. O projeto aqui passa a ser a manutenção do próprio grupo. Contudo, este não assegura sua manutenção, então ocorre a distribuição de tarefas entre seus membros, que caracteriza o grupo como organizado, mas também contribui para que seus membros se aproximem da série, por realizarem suas atividades em prol do grupo, mas isoladamente. Quando o grupo organizado é ameaçado pela série, entra em cena o soberano, aquele que assegurará, pelo controle, a manutenção de seus membros através da imposição de seu projeto individual aos demais. Neste ponto, é ilusão pensar em questão grupal, pois seus membros somente mantêm-se unidos pela opressão, não mais pelo projeto inicial criado por quem dele faz parte. Há uma serialidade disfarçada em grupo.

Sendo assim, série e grupos são interdependentes. Não há como falar no individual e no social sem considerá-los coexistentes. A série forma o social e a ela retorna.

De acordo com o exposto, veremos como poderíamos compor o quadro para análise crítica da Fenomenologiaexistencial direcionada ao contexto do trabalho, Quadro 2, página seguinte.
No quadro anterior mostramos o ser humano sob a concepção de um ser livre, que parece, em princípio, não condizer com o que observamos no mundo do trabalho. Ainda que muitos estranhem esta compreensão, quem com ela se harmoniza, consente que o poder e o controle, enfim o subjugo que permeia as relações sociais e de trabalho, torna-se antítese da liberdade. Esta última só existe por existir obstáculos e vice-versa, como bem colocou Sartre (1960/2002). Logo, o que a princípio pode parecer uma dicotomia, é um paradoxo.

Nesta mesma linha de compreensão, tenho percebido no cotidiano do trabalho, que a necessidade de uma pessoa constranger outra se dá, pela primeira reconhecer e temer a liberdade de escolhas da segunda. A liberdade e a reificação são, da mesma maneira, ameaçadoras. $\mathrm{Na}$ intersubjetividade, a tentativa de objetivar o Outro é uma maneira de se tentar aniquilar a liberdade alheia, porém, como esta última é condição ontológica do ser humano, ela não é extirpada. Estar coagido em sua liberdade é um obstáculo a ser superado pela própria condição de liberdade. Contudo, muitos podem escolher deixar-se coagir pelo medo que sua atitude de enfrentamento provocaria no Outro. Assim, torna-se mais fácil reconhecer ou fingir reconhecer o poder do Outro do que enfrentá-lo. Esta escolha pode significar uma maneira livre do ser humano escolher se proteger, sob algum aspecto. Bem como o opressor, que assim se coloca no mundo por reconhecer, mas não aceitar, a possibilidade do Outro escolher não se sujeitar.

Longe de pensar que tais afirmativas representam uma apologia, de minha parte, ratificante do discurso da resiliência, por vezes convenientemente empregado de maneira equivocada nos meios organizacionais. Pelo contrário, busco aqui lançar foco para a questão do equívoco de se pensar que nas relações de poder e de controle, o controlado esteja privado de sua liberdade de escolha, ficando este sob o poder do controlador. A questão da liberdade trazida por Sartre (1943/2005) volta-se para uma liberdade situada, que se relaciona diretamente com o mundo prático-inerte, como coloca Chauí:

(...) o homem, engaste tenso do interior e do exterior, consciência e corpo, liberdade situada ou facticidade, é uma síntese passiva - o que dele é feito pela situação - e uma síntese ativa - o que ele faz com o que foi feito dele. Ele é a possibilidade igualmente possível da alienação e da verdade, porque é liberdade absoluta (Chauí, 1980, p. 67).

Como menciona a autora acima, o ser humano é livre para deixar-se alienar como para transcender esta situação. A liberdade é uma condição, que visa sempre transcender algum obstáculo ao projeto traçado. A interrelação entre nossos projetos e o prático-inerte nos impele a exercer nossa liberdade na tentativa de transcender o que nos limita, transformando-o em passado, em história. 
Quadro 2 - Critérios para análise crítica da Fenomenologia e do Existencialismo sartreano.

\begin{tabular}{|c|c|}
\hline & PSICOLOGIA DO TRABALHO \\
\hline Referencial & FENOMENOLOGIA E EXISTENCIALISMO \\
\hline Ontologia & $\begin{array}{l}\text { - Consciência intencional mediando a relação indivíduo - mundo (presentificação - iluminação). } \\
\text { - } 0 \text { conhecimento do mundo é uma das possibilidades e uma necessidade do ser humano, porque no mundo "nada é dado ao } \\
\text { homem". } \\
\text { - A liberdade se concretiza na ação. } \\
\text { - a liberdade não é um atributo (ela não nos é dada, somos livres); } \\
\text { - a ação livre é a possibilidade do conhecimento e conseqüentemente da verdade (o Para-si (consciência) ilumina o ser pelo co- } \\
\text { nhecimento); } \\
\text { - a ação e a escolha são de responsabilidade do indivíduo (e não determinadas pela história); } \\
\text { - a liberdade é situada. Desejar algo não significa, necessariamente, sua obtenção; } \\
\text { - a angústia ocorre diante da liberdade. } \\
\text { - Sociabilidade (intersubjetividade) } \\
\text { - as condições históricas determinadas atravessam as relações interpessoais, que influenciam o processo de subjetivação e obje- } \\
\text { tivação do ser do indivíduo no mundo; } \\
\text { - a relaçãa com o mundo se dá na tentativa da busca pela superação desta alienação; } \\
\text { - os conflitos são ocasionados pela dificuldade de reconhecimento do Outro enquanto liberdade; } \\
\text { - tentativa de controle da liberdade do Outro (modos de objetivação). Exemplo: assédio moral, práticas discursivas (p.e., vestir } \\
\text { a camisa da empresa), produções de sentido (p.e. o valor está na quantidade de produção, o grupo enquanto "Ser"), discursos } \\
\text { científicos (p. e. qualidade total). Essas e outras ações expropriam o projeto individual para que o indivíduo realize o projeto do } \\
\text { Outro. Mantém o Para-si na ignorância, uma vez que o conhecimento vem de fora; } \\
\text { - é por causa da escassez do mundo prático-inerte que as relações se tornam desumanas, e o controle da liberdade pode perpassar } \\
\text { pela promessa do Outro em suprir nossas necessidades. }\end{array}$ \\
\hline Epistemologia & $\begin{array}{l}\text { - Compreensiva } \\
\text { - Reflexiva. }\end{array}$ \\
\hline Ser Humano & $\begin{array}{l}\text { - Indeterminado. Não há natureza humana que o defina (essência). Este se define pela sua condição humana. } \\
\text { - Sua existência precede sua essência. (Parte do nada, da liberdade para se construir) } \\
\text { - Inacabado. Projeto, vir-a-ser, totalização-em-curso. } \\
\text { - Livre para criar sua essência. (Constrói sua identidade ao longo de sua existência) } \\
\text { - Responsável por suas escolhas. } \\
\text { - Irredutível ao conhecimento. } \\
\text { - Construtor da sua história e não determinado por ela. }\end{array}$ \\
\hline Ética e Moral & $\begin{array}{l}\text { - } 0 \text { homem responsável como fundamento da ética. } \\
\text { - Moral da ação. } \\
\text { - Binômio liberdade-responsabilidade. }\end{array}$ \\
\hline $\begin{array}{l}\text { Ação / Mudan- } \\
\text { ça }\end{array}$ & $\begin{array}{l}\text { - Ação como crítica aos modos de objetivação (exteriorização do interior) e subjetivação (interiorização do exterior). } \\
\text { - Desveladora da alienação da liberdade da consciência, que "[...] pode modificar os resultados da ação, mas não sua realidade pro- } \\
\text { - Dunda" (Sartre, 1987, p. 151). } \\
\text { - Desveladora da condição homogeinizadora pelo modo de vida globalizado. } \\
\text { - Encoladora da necessidade do reconhecimento do Outro enquanto liberdade. } \\
\text { trabalho. } \\
\text { - Mudanças nas relações de trabalho só podem ocorrer se cada indivíduo tiver consciência de seu projeto com seu trabalho, com a } \\
\text { organização/instituição e com seus parceiros, bem como do projeto de grupos (desalienacão). }\end{array}$ \\
\hline Práticas & $\begin{array}{l}\text { - Utilização da pesquisa fenomenológica e do método progressivo regressivo para compreensão, respectivamente, de como o mundo } \\
\text { aparece para o trabalhador enquanto fenômeno e de suas experiências concretas no cotidiano do mundo do trabalho. } \\
\text { - Intervenções direcionadas a promoção da tomada de consciência pelo trabalhador elou pelos integrantes de grupos sobre: } \\
\text { - } 1 \text { - como significam o mundo do trabalho (o homem como construtor de sua história, não estando seus fazeres presentes e futuros } \\
\text { determinados por ela); } \\
\text { - } 2 \text { - qual(quais) é(são) o(s) projeto(s) individual(is), do grupo e da organização/instituição voltados ao contexto do trabalho; } \\
\text { - } 3 \text { - como transcende(m) individualmente e com Outros (em grupo), as tensões entre seu mundo interno e o externo e; } \\
\text { - } 4 \text { - a importância da alteridade e da reciprocidade positiva. } \\
\text { - A tomada de consciência dará base para possíveis novas ações que podem contribuir com a transcendência do prático-inerte. }\end{array}$ \\
\hline
\end{tabular}


A esta questão, acrescenta Viana:

O ser humano continua, dentro da situação e dos condicionamentos, a ter que fazer escolhas. Ele vai constantemente superando sua situação. O homem continua sendo um projeto em ato. Somente o projeto pode explicar a história, a criatividade humana. Desta forma, Sartre redefine sua concepção de homem apresentando tanto a realidade da situação e seus condicionamentos quanto sua liberdade através do projeto... Sartre reconhece, simultaneamente, as determinações e a liberdade humana. Mas não abre mão de conceber o homem como ser livre, como projeto (Viana, 2008, p. 151).

Muitos associam a questão da liberdade de escolha com a culpabilização do indivíduo. Creio que o entendimento da liberdade sartreana não deva seguir o viés do julgamento, da sentença; mas sim da responsabilidade e do reconhecimento do poder do ser humano por escolher-se.

Vivemos em um momento sócio-histórico que institui, como nunca, padrões de condutas que buscam destituir do indivíduo sua condição humana de ser livre, que incita as relações de poder com mecanismos, muitas vezes obscuros, de controle da liberdade, e que esvazia a intersubjetividade em prol de normatizações sociais. Por isso é que emerge e urge, na Psicologia, olhares denunciadores destas práxis, bem como o incentivo por projetos que buscam transcendê-las. O olhar fenomenológico-existencial então, direcionado às relações de, no e com o trabalho, se compromete com este projeto, como diversos outros olhares de cunho crítico.

Veremos a seguir como podemos, balizados por esta concepção, compreender e atuar, como psicólogos, dentro de alguns contextos no mundo do trabalho.

\section{A Prática do Psicólogo como Engajamento à Superação das Contradições das Práxis Capitalistas}

Podemos supor, em princípio, que o mundo do trabalho apoiado pelos valores capitalistas, coloca o Psicólogo do Trabalho em uma condição de tensão entre os valores atribuídos aos bens materiais e ao humano. Contudo, a matéria (coisa em-si) não pode instituir valor a si mesmo. Para ter seu valor precisa de uma consciência intencionada. Assim, é o próprio ser humano que institui os valores do mundo (coisa, matéria) e de si próprio.

Uma dessas grandes tensões é causada pelas contradições das práxis econômica e social capitalistas, que subordinam o trabalho ao capital através da livre concorrência do mercado. Sendo a consciência um vazio, um nada, o projeto do indivíduo com o mundo, neste caso com e através do seu trabalho, propõe preencher esta falta, migrando de uma falta à outra a preencher através da busca de uma totalidade a executar. Estar consciente é ter trabalhos a executar, haja vista que qualquer ação prática decorre da descoberta de que existem atos-por-fazer-e-ainda-não-realizados (Perdigão, 1995). No entanto, quando as práxis capitalistas visam, a princípio, o salário em troca da ação do trabalhador, institui o salário como condição, a priori, para o preenchimento de muitas de suas faltas. Não obstante, o salário, enquanto dinheiro em-si, não é onipotente para totalizar o indivíduo, sendo assim, este último sempre terá faltas a serem preenchidas.

Destarte, para que os projetos capitalistas sejam atingidos, aqueles que ocupam um lugar de hegemonia e comungam com a primazia do investimento lucrativo do capital sobre o trabalho, percebem que o dinheiro não é o único objeto visado pelo trabalhador. Vários podem ser os objetos no mundo eleitos pelo trabalhador como motivos para sua satisfação.

Assim, diante do enigma do vazio, da negatividade da consciência que lhe dá a liberdade de eleição do mundo, é que as práxis capitalistas visam também projetos de controle dessa liberdade, de maneira que, quando ao criar seus projetos, o indivíduo os direcione ao contexto da produção e do consumo.

Várias são as saídas inventadas para alienar o indivíduo, fazendo com que este esteja fora de si, realizando projetos que não são os seus, mas fins impostos por Outros (Perdigão, 1995), dentre os quais podemos citar grande influência do marketing, da mídia e da moda sobre tais invenções. Não somente estas disciplinas, mas a Administração e a Psicologia também muito contribuíram com essa alienação, podendo ressaltar as teorias sobre Motivação que acreditam estarem no mundo as coisas que podem motivar o trabalhador e por esta crença, o oportunismo de alguns se vale para construir projetos que motivem os trabalhadores.

Em termos fundamentais, a tentativa de controle e posse da consciência alheia, segundo Sartre (1943/2005), é exercida de duas maneiras: (1) ser para o outro, de acordo com o que eu considero que ele espera de mim, buscando assimilar a visão que o Outro possui de mim e; (2) contra atacar o seu olhar, transformando-o em alguém que desejo que seja para mim, buscando vê-lo apenas como um Outro objetivado.

Para manter seus fins, as práxis capitalistas devem exercer ambas formas de controle. A primeira é necessária para que a conduta de posse da liberdade não seja associada à tirania. A globalização e a tecnologia são dois destes exemplos. A possibilidade de transcender os limites do prático-inerte leva ao indivíduo a sensação de aumento de suas opções. Temos por um lado, uma visão de que esta amplitude de possibilidades é algo muito bom; mas por outro, e, lançando mão da segunda conduta de posse, os projetos capitalistas fazem com que o indivíduo acredite que precisa obter o que lhe é ofertado, mas para tal é necessário que produza e consuma, o que lhe escraviza novamente às formas de obtenção. 
Há uma subjetivação da idéia do super-homem e da super-mulher. Muitos tomam este projeto para si, alienando-se diante dos seus próprios. E, sobremaneira, as possibilidades oferecidas tornam-se ideais, ilusoriamente passam a ser perseguidas, sem se perceber o custobenefício, e os danos à saúde física e mental, haja vista que, muitas vezes, o ideal está bem distante do real, cujas limitações deixam marcas maciças na existência física e psíquica.

Também com a globalização, as ofertas de possibilidades não só ampliam, mas mudam rapidamente. Com isso, não há mais tempo de se rever projetos a fim de aprimorá-los. A chamada é para que se criem projetos incessantemente. Por vezes, mal se atinge um, estimula-se a necessidade de criação de outros. Assim, cria-se uma cultura do nadismo, aumentando a vivência do vazio existencial, e com isso, várias comorbidades, como a depressão, estresse, transtorno do pânico, fobias, dentre várias outras que intensificaram seu aparecimento. A necessidade de se preencher o vazio acaba por não ser compreendida como algo ontológico do ser humano, um ponto de referência interno (o vazio da consciência) que necessita do mundo para ser preenchido, mas ao contrário, o foco é dado antes no objeto, para se depois criar a ilusão dessa ou daquela necessidade.

A liberdade já é um fardo, como disse Sartre (1960/2002). Ser livre é viver a angústia da responsabilidade da escolha sem conhecer as conseqüências desta. A liberdade é causadora de mal estar, pois a única escolha que não podemos fazer é não escolher ser livre. Imaginemos quando nos defrontamos com uma amplitude de possibilidades criadas por outrem para nós. Se, quando somos nós que as criamos não escapamos dos conflitos existenciais, quiçá quando as opções são criadas e ofertadas por Outros com condições e critérios de escolhas preestabelecidos. O problema neste caso, não é, fundamentalmente, o de limitarem as opções de escolhas, uma vez que para muitos esta é uma situação confortável, mas reside em escolherem por mim o que devo me identificar, o que reside na estratégia do outro negar minha condição humana de ser livre, logo de escolher pelo que eu me identifico.

Estar consciente do que se quer, a fim de se construir um projeto próprio que não vá ao encontro dos projetos capitalistas, parece não ser uma boa escolha para aqueles que não querem se sentir excluídos. Para Sartre (1943/2005) a liberdade de escolha não quer dizer obtenção, mas sim a liberdade de eleição. Esta máxima colide com a máxima capitalista, haja vista que para esta, o ter sobrepõe ao ser. Com isso, é como se devêssemos escolher sempre o ter para poder ser. Os valores são atribuídos a pontos de referências externos, agregados que estão aos produtos, ao conhecimento, ao status social, dentre outros artifícios que servem como iscas para a manutenção do capital.
A amplitude de opções é saudável para o ser humano, mas a falta de oportunidade para criar uma tradição com o que se escolhe não oportuniza o indivíduo de ver suas escolhas escritas na história e como algo que, ao se tornar história, pode ser escolhida também como um futuro a ser perseguido, ou seja, um projeto de sua geração e de outros. Um futuro concreto e alcançável aparece como algo perseguido, mas quase que inatingível. E como nossas escolhas têm o futuro, o projeto, como seu fundamento, viver a sensação do que melhor escolher dentre várias opções e tentar adivinhar qual delas dará uma garantia melhor de um futuro mais seguro, ainda que, no futuro a escolha atual pode não ter mais o valor necessário, pode suscitar vivências de desproteção, desamparo, solidão, instabilidade e aniquilamento com o Projeto de ser. $\mathrm{O}$ sentido da vida pode tornar-se sem sentido.

Também consciente deste aniquilamento do sentido da vida, que as práxis capitalistas buscam, elas próprias, eleger o sentido de sua vida, valorizando e escolhendo para você a partir do que é de maior valor para elas. Isso porque há a idéia (essência) preconcebida de quem o outro deve ser, ou seja, já existe uma subjetivação do Ser do capital. Ao contrário do que prega a ética (moral) existencialista, cuja liberdade parte do nada, sem nenhuma idéia que preceda a existência do indivíduo.

Por outro lado, lidar com a liberdade alheia é tanto um problema para aqueles que desejam impor suas verdades e necessidades, quanto para aqueles que são alvo do controle de sua liberdade. Reportando as relações de trabalho tanto no âmbito privado quanto no público, os projetos institucionais e organizacionais, sejam em quaisquer desses setores da economia e em quaisquer níveis, tendem a ser escolhidos por alguns que precisam de outros para que sejam atingidos. É no bojo da sociabilidade, construída por esta interdependência das pessoas que estarão envolvidas com os projetos, bem como pelo que será instituído pelo social, que facilitará ou não uma boa qualidade de vida no trabalho.

O sofrimento psíquico, segundo a concepção sartreana da existência, é um processo criado nas relações concretas do sujeito, na sua relação dialética com o social (o estanque) e o sociológico (o processo). Os profissionais que se identificam com Psicologia do Trabalho, enquanto a $3^{\mathrm{a}}$ vertente da Psicologia no contexto do trabalho, direcionam seus projetos à saúde física e mental do trabalhador. Suas consciências captaram no mundo a grande dificuldade dos trabalhadores transcenderem 0 mundo prático-inerte do trabalho através de saídas próprias, podendo ser consideradas mais saudáveis, haja vista que seriam motivadas por suas necessidades reais, inclusive a maior, que é a de exercer a sua liberdade sem opressão. Com esta possibilidade restrita e quando são delegados a segundo plano em detrimento ao capital, parece que houve um aumento gradativo de adoecimento dos trabalhadores. 
A escassez de bens materiais, como colocado no início deste artigo, sugere neste caso, tornar-se escassez da possibilidade de invenção de saídas pelo próprio trabalhador, uma vez que tendem a ser oferecidas pela própria práxis capitalista.

No quadro 1 podemos observar os fundamentos dos projetos dos profissionais da Psicologia do Trabalho. Alguns se enveredam pelas políticas públicas, outros diretamente no tratamento da saúde mental e outros buscam dar voz ao trabalhador, mas todos têm um projeto em comum: o de se engajarem, através de suas ações, na busca de ajudar a transcender os determinantes sóciohistóricos de cada relação no e do trabalho, que contribuem com o aparecimento de doenças.

Na utilização da Fenomenologia-existencial, o engajamento com este projeto dá-se com o objetivo de que o psicólogo ajude o trabalhador a ter consciência reflexiva de seus projetos, que, muitas das vezes, podem ser alienados, para que assim ele possa escolher de maneira consciente e responsável, conjugando suas escolhas com o contexto em que se situa; saídas essas, como Sartre (1943/2005) diz, dentro dos possíveis, uma vez que a liberdade é situada.

\section{Considerações Finais}

Podemos observar os paradigmas sobre o mundo do trabalho através da própria história construída pelo ser humano para este. $\mathrm{O}$ valor à adaptação do ser humano a função, na Psicologia Industrial; da adaptação ao meio interno e externo a organização, na Psicologia Organizacional e, atualmente, à saúde mental do trabalhador, na Psicologia do Trabalho. Mesmo quando contamos a história de como foram construídos estes olhares da Psicologia no contexto do trabalho, não podemos considerá-los como passado, haja vista que ainda co-existem construindo suas histórias nesse contexto.

Todavia, considero difícil o psicólogo do trabalho que possui a consciência das contradições das práxis capitalistas, atender às demandas da Psicologia Industrial e da Organizacional, sem angustias. Mesmo que as atividades construídas em cada uma delas tenham inovado suas técnicas e instrumentos, os modelos parecem-me bem definidos quanto aos valores atribuídos ao ser humano em detrimento ao capital. Sendo assim, as ações do psicólogo se fundamentarão naquela(s) que se identificam com as suas.

Diante de todo o exposto, o psicólogo do trabalho ao ajudar o trabalhador a transcender suas tensões entre o mundo interno e externo, também como trabalhador tem os seus valores balizando as suas próprias tensões nesse contexto.

Algumas concepções de cunho naturalista tendem a promover a idéia sobre a neutralidade do psicólogo em suas práticas. Portanto, se falamos da consciência que se orienta ao mundo, como o psicólogo pode abster-se, durante seu trabalho, de dar ao contexto seu significado?

Pautando-se no paradigma da consciência intencional, sempre atribuirá valores e significados às coisas, aos contextos, às relações, a tudo a que sua consciência se dirige. Por isso, apoiando-se na Fenomenologia-existencial, acreditamos que há a necessidade de: (1) o profissional ter também consciência reflexiva sobre como significa o mundo, os valores que atribui às coisas que nele se situam, principalmente às familiares, as que fazem parte do nosso cotidiano, haja vista que são as que menos nos espantam, logo a que menos percebemos (Morris, 2009), e como ele próprio transcende as tensões de seu mundo interno e o externo, para que possa, no exercício de sua profissão; (2) saber como poderá gerir as tensões originadas na intersubjetividade; (3) sem considerar-se imaculado a essas; (4) reconhecendo também suas limitações, a fim de valorizar a alteridade, também através do trabalho interdisciplinar e; (5) a utilização do método fenomenológico e do método progressivo regressivo ajudará, tanto o psicólogo quanto o outro trabalhador, a desvelarem os preconceitos que os impedem de conhecer o que reconhecem como verdadeiro, na maioria das vezes, verdades ratificadoras do prático-inerte e; na busca pela superação desses preconceitos há o engajamento do psicólogo com outros trabalhadores para a modificação da maneira pela qual vivem. Lidando com as tensões internas e externas, dentro dos seus possíveis, haverá a possibilidade de transcender o prático-inerte, e com isso, a construção de mais uma história para e no mundo do trabalho.

\section{Referências}

Beauvoir, S. (1984). A força da idade. Rio de Janeiro: Nova Fronteira. (Originalmente publicado em 1961).

Carmo, P. S. do. (2005). As ideologias do trabalho (2. ed.). São Paulo: Ed. Moderna.

Chauí, M. de S. (1980). Sartre ou da Liberdade. Textos SEAF, 1(1), 64-68.

Galeffi, D. A. (2000). O que é isto - a Fenomenologia de Husserl? Ideação, 5, 13-36.

Guareschi, N. M. de F. \& Freitas, S. M. P. de. (2004). A formação em Psicologia no contexto do trabalho: análise de saberes e suas implicações políticas e sociais. Barbarói, 20, 29-60.

Husserl, E. (1980). Investigações Lógicas: sexta investigação: elementos de uma elucidação fenomenológica do conhecimento (Coleção Os Pensadores, vol. 41). São Paulo: Abril Cultural.

Maheirie, K. \& Pretto, Z. (2007). O movimento progressivoregressivo na dialética universal e singular. Revista do Departamento de Psicologia da UFF, 2(19), 455-462.

Morris, K. J. (2009). Sartre. (E. da R. Marques, Trad.). Porto Alegre/RS: Artmed. 
Jacques, M. da G. C. (2003). Abordagens teórico-metodológicas em saúde/doença mental \& trabalho. Psicologia \& Sociedade, 1(15), 97-116.

Freitas, S. M. P. de (2002). A Psicologia no contexto do trabaIho: uma análise dos saberes e dos fazeres. Dissertação de Mestrado, Pontifícia Universidade Católica do Rio Grande do Sul, Rio Grande do Sul.

Perdigão, P. (1995). Existência e liberdade: uma introdução à Filosofia de Sartre. Porto Alegre/RS: L\&PM.

Sartre, J. P. (1987). O Existencialismo é um humanismo; A imaginação; Questão de Método (Coleção Os Pensadores, 3. ed.). São Paulo: Nova Cultura.

Sartre, J. P. (2002). Crítica da razão dialética: precedido por questões de método (G. J. F. Teixeira, Trad.). Rio de Janeiro: DP\&A. (Originalmente publicado em 1960).

Sartre, J. P. (2005). O Ser e o nada. Ensaio de ontologia fenomenológica (P. Perdigão, Trad.). (13. ed.). Petrópolis/RJ: Vozes. (Originalmente publicado em 1943).

Viana, N. (2008). Sartre e o marxismo. Filosofia, Unisinos, 2(9), 146-161.

Sylvia Mara Pires de Freitas - Psicóloga, Docente da Universidade Estadual de Maringá (UEM/PR) e da Universidade Paranaense (UNIPAR/PR). Mestre em Psicologia Social e da Personalidade pela Pontifícia Universidade Católica do Rio Grande do Sul (PUC-RS). Especialista em Psicologia do Trabalho (CEUCEL-RJ). Formação em Psicologia Clínica na abordagem existencial (NPV/RJ). Endereço para correspondência: Departamento de Psicologia - Universidade Estadual de Maringá. Av. Colombo, 5790. CEP: 87020-900. Maringá / PR, Brasil. E-mail: sylviamara@gmail.com

Recebido em 25.07.09

Aceito em 12.10.09 